\title{
Şehmus Baday
}

Batman University, sehmus.baday@batman.edu.tr, Batman-Turkey Hüdayim Başak

Gazi University, hbasak@gazi.edu.tr, Ankara-Turkey

Fikret Sönmez

Karşıyaka Tüpraş MTAL, sonmezfikret@gmail.com, Kocaeli-Turkey

\begin{tabular}{l|c|c|c}
\hline DOI & \multicolumn{3}{|c}{ http://dx.doi.org/10.12739/NWSA.2017.12.4.2A0122 } \\
\hline ORCID ID & $0000-0003-4208-8779$ & $0000-0001-8066-5384$ & $0000-0003-1718-892 x$ \\
\hline \hline
\end{tabular}

\section{ISIL İŞLEM UYGULANMIŞ ORTA KARBONLU ÇELIKKTE MİKROYAPI DEĞİŞIMININ BULANIK MANTIK İLE TAHMIN EDİLMESİ}

\section{Öz}

Bu çalışmada, su verme işlemi ile mikroyapısı martenzit faza getirilmiş, AISI 1050 orta karbonlu çeliğe üç farklı ısıl işlem sıcaklığı ve üç farklı ısıl işlem süresi uygulanmış ve bu işlemler sonucunda mikroyapıda gözlenen değişimler bulanık mantık ile tahmin edilmiştir. Mikroyapı değişimlerini tahmin etmek için üç farklı sıcaklık $500^{\circ} \mathrm{C}, 600^{\circ} \mathrm{C}$ ve $700^{\circ} \mathrm{C}$ ve üç farklı süre 15, 60 ve 180 dakika giriş parametresi olarak seçilmiştir. Giriş parametrelerine bağlı olarak mikroyapının küreselleşme oranı dilsel ifade olarak hiç, az, orta ve çok sözcükleri ile bulanıklaştırılarak dokuz adet kural oluşturulmuştur. Küreselleştirme oranı tahminlerini yapılabilmesi için Mamdani çıkarım yöntemi kullanılmıştır. Sonuç olarak bulanık mantık ile orta karbonlu çeliğin mikroyapı değişimleri başarılı bir şekilde tahmin edildiği görülmüştür.

Anahtar Kelimeler: Isıl işlem, Mikroyapı, Bulanık Mantık, Orta Karbonlu Çelik, Mamdani Yöntemi

\section{ESTIMATION WITH FUZZY LOGIC OF THE MICROSTRUCTURE CHANGE IN HEAT TREATED MEDIUM CARBON STEEL}

\section{ABSTRACT}

In this study, three different heat treatment temperatures and times have been applied to AISI 1050 medium carbon steel that have been converted to martensite phase by quenching and as result of this heat treatmenets, the changes observed in its microstructure was estimated by fuzzy logic. To predict the microstructure changes have been selected three different temperatures of $500^{\circ} \mathrm{C}, 600^{\circ} \mathrm{C}$ and $700^{\circ} \mathrm{C}$ and three different times of 15, 60 and 180 minutes as input parameters. Depending on the input parameters, the spheroidization rate of the microstructure has been blurred with no, low, medium and high words as linguistic expressions and nine rules were formed. The Mamdani method has been used to estimate the spheroidization rate. As a result, it has been seen that fuzzy logic has successfully predicted microstructure changes of medium carbon steel.

Keywords: Heat treatment, Microstructure, Fuzzy logic, Medium Carbon Steel, Mamdani method 


\section{GIRIŞ (INTRODUCTION)}

Isıl işlemler, katı halde bulunan metal ve alaşımlarına yumuşatma, soğuk şekillendirme, mukavemet artırma gibi özellikler kazandırmak amacıyla ısıl işlem türüne göre birbiri ardına uygulanan ısıtma ve soğutma işlemleridir. Çeliğin yapısında bulunan karbon elementinin miktarı o çeliğin ne tür bir ısıl işlem uygulanması gerektiği hakkında tasarımcılara bilgi vermektedir. Bu amaç ile küreselleştirme ısıl işlemi, orta veya yüksek karbonlu çeliklerin işlenebilirlik, darbe ve süneklik özelliklerini geliştirmek için sıklıkla kullanılmaktadır. Genellikle orta ve yüksek karbonlu çeliklerin işlenebilirliğini artırmak için uygulanan küreselleştirme tavı, sementitin, perlit içinde olduğu gibi levhalar halinde değil, küçük küreye benzer şekilde parçalar halinde oluşmasını sağlar [1 ve 2]. Bu tür çeliklerin işlenmesini kolaylaştırmak ve sünekliğini artırmak amacıyla da küreselleştirme ısıl işlemi uygulanır [3 ve 5]. Kamyabi-Gol ve ark., çalışmalarında mikroyapıları kaba perlit, ince perlit, martenzit ve beynit fazlardaki çeliklere $700^{\circ} \mathrm{C}^{\prime}$ de sabit sıcaklıkta sırasıyla 4, 8, 12 ve 16 saat küreselleştirme ısıl işlemi uygulamışlardır. Mikroyapıda oluşan küreselleşmeleri optik mikroskop ile incelemiş ve metalografik imaj işleme programı kullanarak küreselleşme oranını belirlemişlerdir. Sonuç olarak küreselleşme oranı üzerinde küreselleştirme süresinin daha etkili olduğunu vurgulamışlardır [6].

Gajalakshmi ve ark., yapmış oldukları çalışmada mikroyapıdaki ortalama küresel taneleri destekleyici vektör regresyon kullanarak bir görüntü işleme algoritması geliştirmişlerdir. Otomatik küresel miktarını ölçme algoritması elle saptamaya göre çok daha hızlı bir şekilde uygulamışlardır [7]. Adalı ve ark., $870^{\circ} \mathrm{C}$ de kadar ısıtılmış ve ardindan su verme ve tavlama işlemlerine tabi tutulan AISI 5140 Islah çeliğine $720 \pm 5^{\circ} \mathrm{C}^{\prime}$ de $2,4,8,16$ ve 24 sat süre ile küreselleştirme ısıl işlemi uygulamışlardır. Yapmış oldukları metalografik incelemeler sonucunda su verilmiş ve ardında küreselleştirilmiş numunelerde küreselleştirme 2. saatte başlamış ve 4. saatte mikroyapı tamamen küreselleşmiş olduğunu tespit etmişlerdir. Tavlanmış ve ardından küreselleştirilmiş numuneler ise 8. saatte küreselleşmişlerdir [8]. Altuntaş ve ark., 700MPa basınçta sıkıştırılmış ve $1180^{\circ} \mathrm{C}^{\prime}$ de koruyucu gaz atmosferi altında sinterlenmiş yüksek karbonlu toz metalürjisi çeliğini $850^{\circ} \mathrm{C}^{\prime}$ de 6 dakika östenitlemiş ve ardından oda sıcaklığında su verme yöntemi ile mikroyapı martenzit faza getirilmiştir. Mikroyapıda bulunan ince küresel sementit dağılımını sağlamak için numuneler 505 ve $705^{\circ} \mathrm{C}^{\prime} \mathrm{de}$ sürede ayrı ayrı tavlanmıştır [9]. Barzani ve ark., yüzey pürüzlülük değerlerinin tespitinde Fuzzy logic yöntemini kullanmışlardır [9].

Yüzey bütünlüğü ile ilgili hibrit bir fuzzy logic çalışması gerçekleştiren yazarlar da mevcuttur [10]. Lv ve ark. Yüksek karbonlu çeliği küreselleştirmek için 1043 K'de 5 dakikalık kısa aralar ile ve 953K sıcaklıkta 3 dakikalık kısa aralar ile kademeli olarak ısıl işlem uygulamışlardır. Mikroyapıda küreselleşen sementitlerin ortalama oranları çevrim sayısı artıkça artmaktadır. Beş döngüden sonra mikroyapı sementitler tam olarak küreselleşmekte olduğunu tespit etmişlerdir [11]. İbrahim ve ark., çalışmalarında iş parçası üzerinde haddeleme parametrelerinin yüzey pürüzlülüğü üzerinde etkilerini fuzzy logic yöntemi ile araştırmışlardır [12]. Fedai ve ark., frezeleme operasyonlarında, optimum kesme parametreleri tespit etmek için yapay zeka sistemlerinden meydana gelen bir adaptif sanal operatör geliştirmişlerdir. İşleme esnasında meydana gelen takım aşınması, yüzey pürüzlülüğü ile diğer bozucu etmenler dikkate alınarak 
oluşturulan adaptif sistem kendini sürekli olarak güncellemektedir [13].

\section{2. ÇALIŞMANIN ÖNEMI (RESEARCH SIGNIFICANCE)} farklı sıcaklık ve sürelerde ısıl işlem uygulayarak mikroyapıda meydana gelen küresel sementitlerin oranını sözel ifadeler ile bulanıklaştırarak tahmin etmek olarak belirlenmiştir. Ayrıca çalışmanın bir diğer amacı, ara sıcaklık ve sürelerde mikroyapıda ne oranda küreselleşmenin meydana geldiğini tespit etme hedefi de bulunmaktadır.

\section{MATERYAL ve METOD (MATERIALS and METHOD)}

Küreselleştirme ısıl işlemlerini gerçekleştirmek için günümüz imalat sanayisinde yaygın olarak kullanılan orta karbonlu AISI 1050 çelik malzemesi seçilmiştir. Bu orta karbonlu çeliğin sahip olduğu kimyasal bileşim Tablo 1'de verilmiştir. İ̧̧leme deneylerinde, 6 metre uzunluğa sahip içi dolu çelik malzemeden $\varnothing 30 \times 200 \mathrm{~mm}$ boyutlarında kesilen numuneler ısıl işlem fırınında tavlanmak için hazır hale getirilmiştir.

Tablo 1. AISI 1050 Çeliğinin kimyasal bileşimi (Ağırlıkça o)

(Table 1. The chemical composition of AISI 1050 Steel ( $\frac{0}{0}$ by weight))

\begin{tabular}{|c|c|c|c|c|c|c|c|c|c|c|c|}
\hline $\mathrm{C}$ & $\mathrm{Si}$ & $\mathrm{Mn}$ & $\mathrm{P}$ & $\mathrm{S}$ & $\mathrm{Cr}$ & $\mathrm{Mo}$ & $\mathrm{Ni}$ & $\mathrm{Al}$ & $\mathrm{Cu}$ & $\mathrm{Sn}$ & $\mathrm{Fe}$ \\
\hline 0.52 & 0.28 & 0.81 & 0.009 & 0.022 & 0.08 & 0.02 & 0.10 & 0.020 & 0.17 & 0.011 & $\mathrm{Kalan}$ \\
\hline
\end{tabular}

AISI 1050 çeliğine ait SEM görüntüsü Şekil 1'de verilmiştir. Şekil 1'deki mikroyapı ferit matrisi üzerinde ince perlittik fazdan oluşmaktadır.

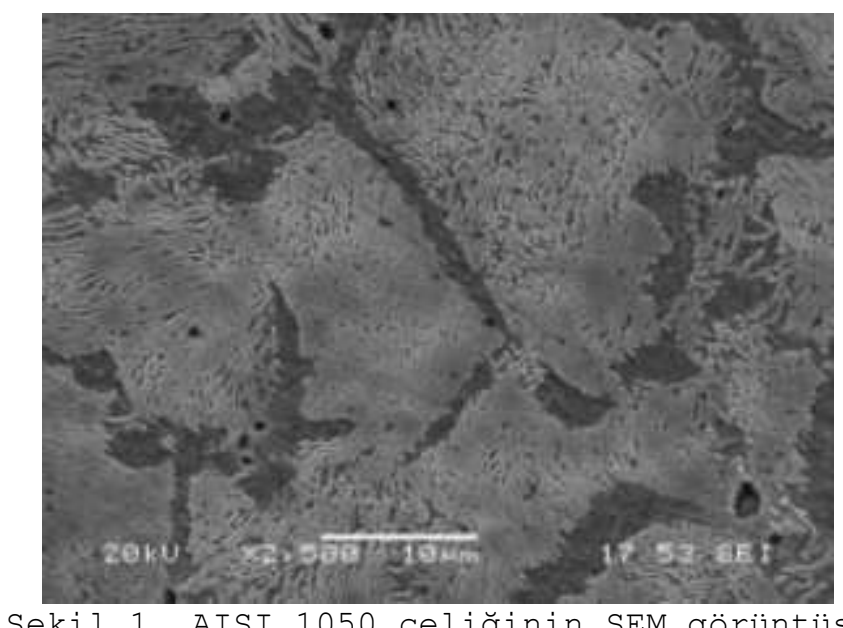

Şekil 1. AISI 1050 çeliğinin SEM görüntüsü

(Figure 1. SEM image of AISI 1050 steel)

Isıl işlemler için hazırlanan $\varnothing 30 \times 200 \mathrm{~mm}$ boyutlarında kesilen numuneler östenitik faz elde etmek için orta karbonlu çeliğin içinde barındırdığı karbon miktarı göz önünde bulundurularak ilk aşamada $850^{\circ} \mathrm{C}$ sıcaklıkta hazır hale getirilmiş ısıl işlem fırınında 15 dakika bekletilmiştir. Östenetik faza getirilen numuneler fırından alınıp hiç zaman kaybetmeden su verme yöntemi ile mikroyapıda martenzitik faz elde edilmiştir. Daha sonra her bir numuneye sırasıyla $500^{\circ} \mathrm{C}, 600^{\circ} \mathrm{C}, 700^{\circ} \mathrm{C}$ ısıl işlem sıcaklığında, 15,60 ve 180 dakika ısıl işlem süresi ile izotermal tavlamaya tabi tutularak numunelerin mikroyapısında bulunan ferritik matris içerisinde farklı morfoloji ve ebatlara sahip küresel sementitler elde edilmiştir. Küreselleştirme ısıl işlemi ile değişen 
mikroyapı farklılıklarını açığa çıkartmak için numunelere standart metalografik yöntemler uygulanmıştır. 이나 Nital dağlayıcı kullanılarak mikroyapılar açığa çıkartılmıştır. Mikroyapıların görüntülenmesinde Jeol 6060 JSM-LV Tarama Elektron Mikroskobu (SEM) kullanılmıştır. Orta karbonlu AISI 1050 çeliğinin mikroyapısında oluşan küresel sementit oranı MATLAB programlama dili kullanılarak gerçekleştirilmiştir.

\section{BULANIK MANTIK VE KURAL TABANI (FUZZY LOGIC AND THE RULE BASE)}

Bulanık mantık terimi yaklaşık olarak 20. yüzyılın ortalarında Zadeh tarafından olasılık ve mantık teorilerine alternatif olarak geliştirmiştir [14 ve 16]. Klasik mantıkta bir şey ya tümüyle siyahtır ya da beyazdır. Fakat bulanık mantık sisteminde göre ise bir şey kısmen siyah ya da kısmen beyaz olabilir [15]. Bulanık mantık sistemleri klasik kümeyle karşılaştırıldığında, kümeye ait elemanların bu kümeye ait olma olasılığının 0 ve 1 değerler arasındaki değerleri alabilen sürekli bir üyelik fonksiyonu ile ifade edilirken, klasik küme elemanlarının bu kümeye ait ise evet ya da hayır kesin cevapları verilmesidir [14]. Buna ilaveten matematiksel olarak ifade edilen nicel analizlere başvurulmadan insan tecrübeleri ve bilgileri nitel olarak da ifade edilebilir. Başka bir ifade ile bulanık mantık sistemleri matematiksel olarak kesin sınırı belli olan değerleri sözel ifadeler ile bulanıklaştırma işlemidir [17]. AISI 1050 orta karbonlu çeliğin mikroyapısındaki sementitlerin küreselleşme oranını tahmin etmek için giriş parametreleri olarak ısıl işlem sıcaklığı ve ısıl işlem süresi alınmıştır. Matlab programlama dili aracılığıyla oluşturulan bulanık mantık fonksiyonları, giriş ve çıkış parametrelerinin grafiksel olarak gösterimi Şekil 2'de verilmiştir. Bulanık mantığa ait farklı fonksiyonlar bulunmaktadır. Bu fonksiyonlar üçgen, trapez, Gaussian ve Sigmoid fonksiyonlarıdır. Bu çalışmada, giriş parametreleri olan sıcaklık ve süre Gaussian fonksiyonu kullanılırken, çıkış parametresi olan küreselleşme oranı için ise üçgen fonksiyon kullanılmıştır.

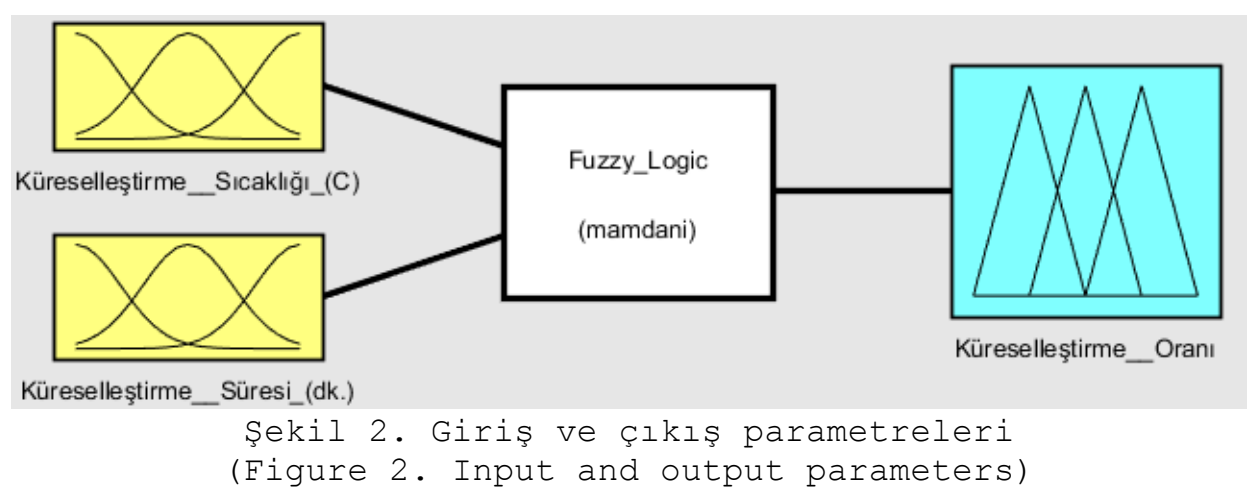

ÜÇ farklı sıcaklık $500^{\circ} \mathrm{C}, 600^{\circ} \mathrm{C}$ ve $700^{\circ} \mathrm{C}$ ve üç farklı süre 15 , 60 ve 180 dakika şartlarına bağlı olarak oluşan kural tabanları Şekil 3'te verilmiştir. Bu parametrelere bağlı olarak mikroyapının küreselleşme oranı dilsel ifade olarak hiç, az, orta ve çok sözcükleri ile bulanıklaştırılarak dokuz adet kural oluşturulmuştur. 


\begin{tabular}{|c|c|c|}
\hline 1. If (Küresellestirme & Sıcaklığı (C) is 500) and (Küresellestirme & Süresi (dk.) is $15 \mathrm{~min}$ ) then (Küresellestirme Oranı is None) (1) \\
\hline 2. If (Küreselleştirme & SIcaklığı_(C) is 500 ) and (Küreselleştirme & _Süresi_(dk.) is $60 \mathrm{~min}$ ) then (Küreselleştirme_Oranı is None) (1) \\
\hline & Küreselleştirme_ & _Süresi_(dk.) is $180 \mathrm{~min}$ ) then (Küreselleştirme_Ora \\
\hline 4. If (Küreselleştirme] & SIcaklığı_(C & Küreselleştirme_Orar \\
\hline 5. If & Sıcaklığı_(C) is 600) and (Küreselleştirme & Süresi_(dk.) is 60min) then (Küreselleştirme_Oranı is \\
\hline & SIC & (Küreselleştirme_O \\
\hline me & Sid & rme_Ora \\
\hline 8. If & |lğı_(C) is & ledium-High) (1) \\
\hline 9. If (Küreselleştirme_ & Sıcaklığı_(C) is 700) and (Küreselleştirme & Süresi_(dk.) is $180 \mathrm{~min}$ ) then (Küreselleştirme__oranı is High) (1) \\
\hline
\end{tabular}

Şekil 3. Bulanık mantık kuralları

(Figure 3. The rules of fuzzy logic)

Kural $1^{\prime}$ de $500^{\circ} \mathrm{C}$ ve 15 dakika ısıl işlem uygulanırsa o zaman çeliğin mikroyapısında hiç küreselleşme meydana gelmeyecektir. Kural 5: Eğer $600^{\circ} \mathrm{C}$ ve 60 dakika süre ile işlem uygulanırsa orta seviyede küreselleşme meydana gelecektir. Kural 9: Eğer $700^{\circ} \mathrm{C}$ ve 180 dakika süre olursa o zaman mikroyapı tam küreselleşecek şeklinde dilsel ifadeler kullanarak bulanık sistem kuralları oluşturulmuştur.

\section{DENEYSEL BULGULAR VE DEĞERLENDİRİLMESİ (EXPERIMENTAL RESULTS AND EVALUATION)}

Üç farklı küreselleştirme sıcaklığı ve üç farklı ısıl işlem süresine bağlı olarak oluşturulan bulanık mantık kural tabalarına bağlı olarak oluşturulan grafikler Şekil 4, 6, 8 ve 10'da verilmiştir. Küreselleştirme oranının tespiti için oluşturulan Kural 1 Şekil 4'de görülmektedir. Sözel ifade olarak bulanıklaştırılan mikroyapının küreselleşmesi Kural $1^{\prime}$ de $500^{\circ} \mathrm{C}$ ve 15 dakika süre olarak ifade edilmiştir. Bulanık mantık sistemi tarafından tahmin edilen küreselleştirme oranı sayısal değer olarak 0.0946 denk gelmektedir. Ayrıca Kural $1^{\prime}$ e ait $500^{\circ} \mathrm{C}$ ve 15 dakika çeliğinin SEM görüntüsü Şekil 5'te görülmektedir. Şekil 5'deki SEM görüntüsünden de anlaşıldığı gibi mikroyapıda küreselleşme oldukça az meydana gelmiş hatta küreselleşme neredeyse hiç gerçekleşmemiştir.

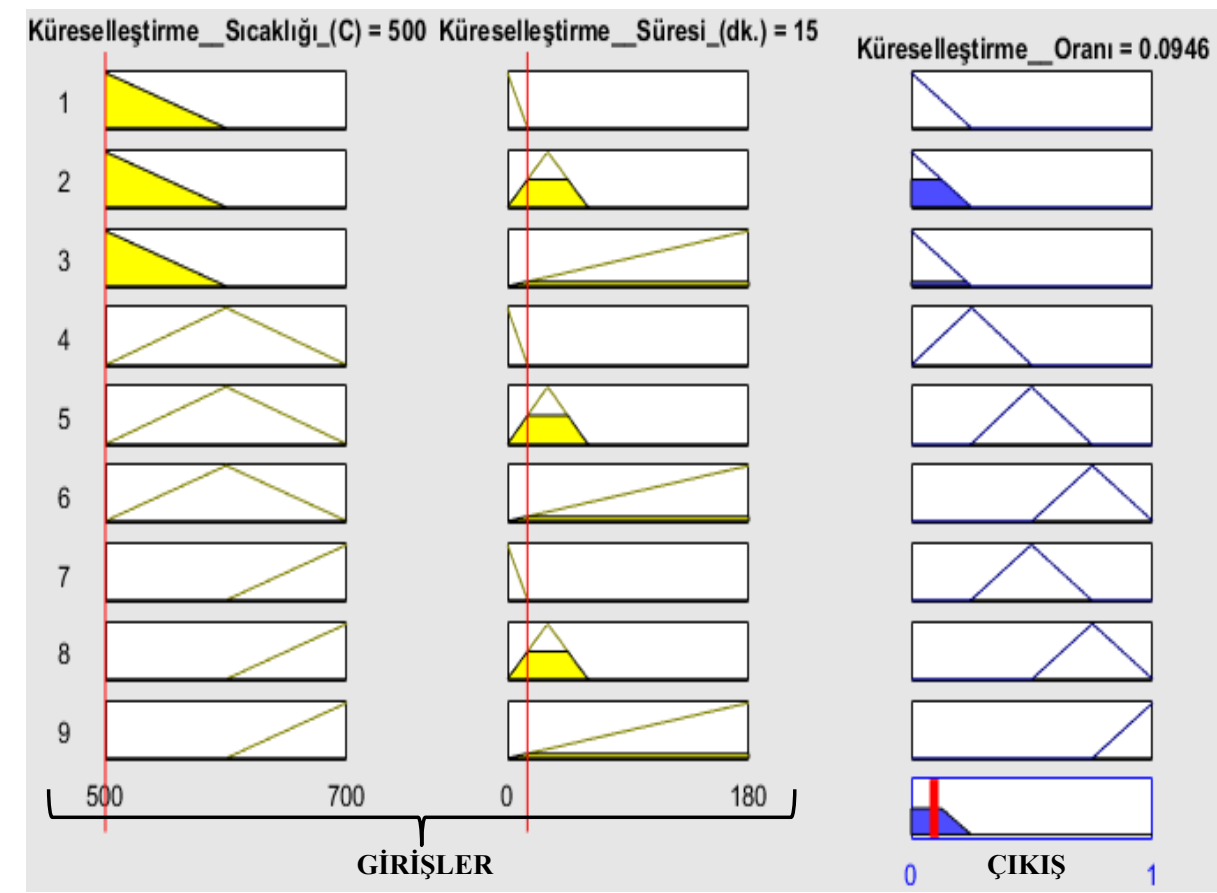

Şekil 4. Kural 1: Grafiksel gösterimi

(Figure 4. Rule 1: Graphical representation) 


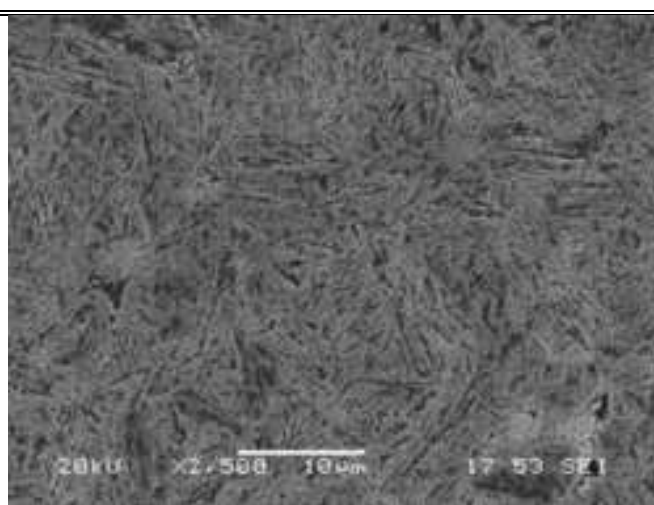

Şekil 5. AISI $1050^{\prime}$ in $500^{\circ} \mathrm{C}$ ve 15 dakikadaki SEM görüntüsü (Figure 5. SEM imagine of AISI 1050 at $500^{\circ} \mathrm{C}$ and 15 minutes)

Bulanık mantık tabanlı oluşturulan Kural 5'e göre mikroyapının ne oranda küreselleştirdiğini gösteren grafikler şekil 6'da verilmiştir. Şekil 6'da anlaşıldığı gibi küreselleşme oranı oldukça iyi bir seviyede oluştuğunu göstermektedir. Küreselleşme oranı Kural l'e göre oldukça iyi bir orana yani 0.75 yükseldiği Şekil 6'da görülmektedir. Bu kural tabanın tahmin oranını bir göstergesi olan SEM görüntüsü Şekilde 7'de verilmiştir. Bu mikroyapıda lamelli perlitik yapının parçalanarak küresel sementitlere dönüştüğü görülmektedir.

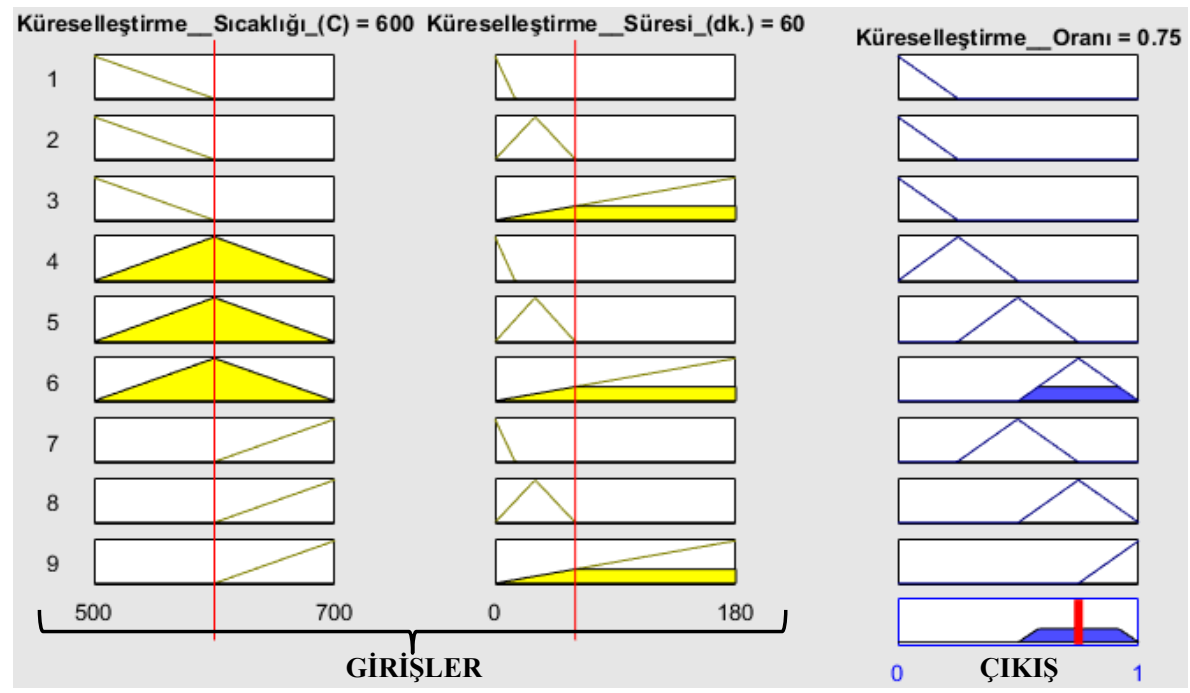

Şekil 6. Kural 5: Grafiksel gösterimi

(Figure 6. Rule 5: Graphical representation)

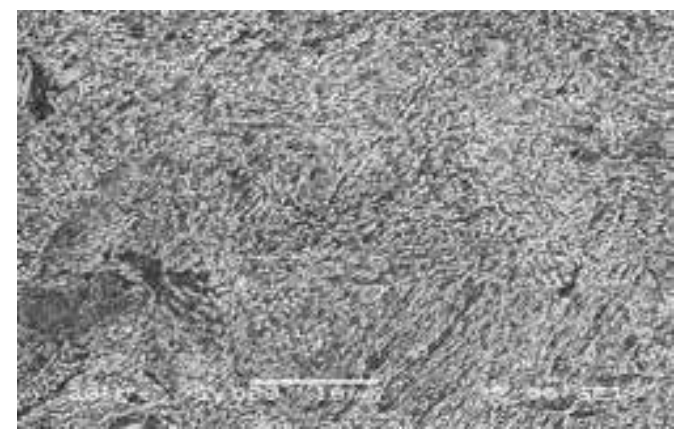

Şekil 7. AISI $1050^{\prime}$ in $600^{\circ} \mathrm{C}$ ve 60 dakikadaki SEM görüntüsü

(Figure 7. SEM imagine of AISI 1050 at $600^{\circ} \mathrm{C}$ and 60 minutes) 
Bir diğer kural tabanına göre elde edilen grafikler Şekil 8'de görülmektedir. Şekil 8'deki Kural 9'a göre elde edilen oran 0.92 seviyelerine kadar yükselmektedir. Bu oran mikroyapının küreselleşme oranın en yüksek seviyede oluştuğunun bir göstergesidir. Bu durumu elde edilen SEM görüntüsü sonucu ile uyum içinde olduğu Şekil 9'da net bir şekilde görülmektedir.

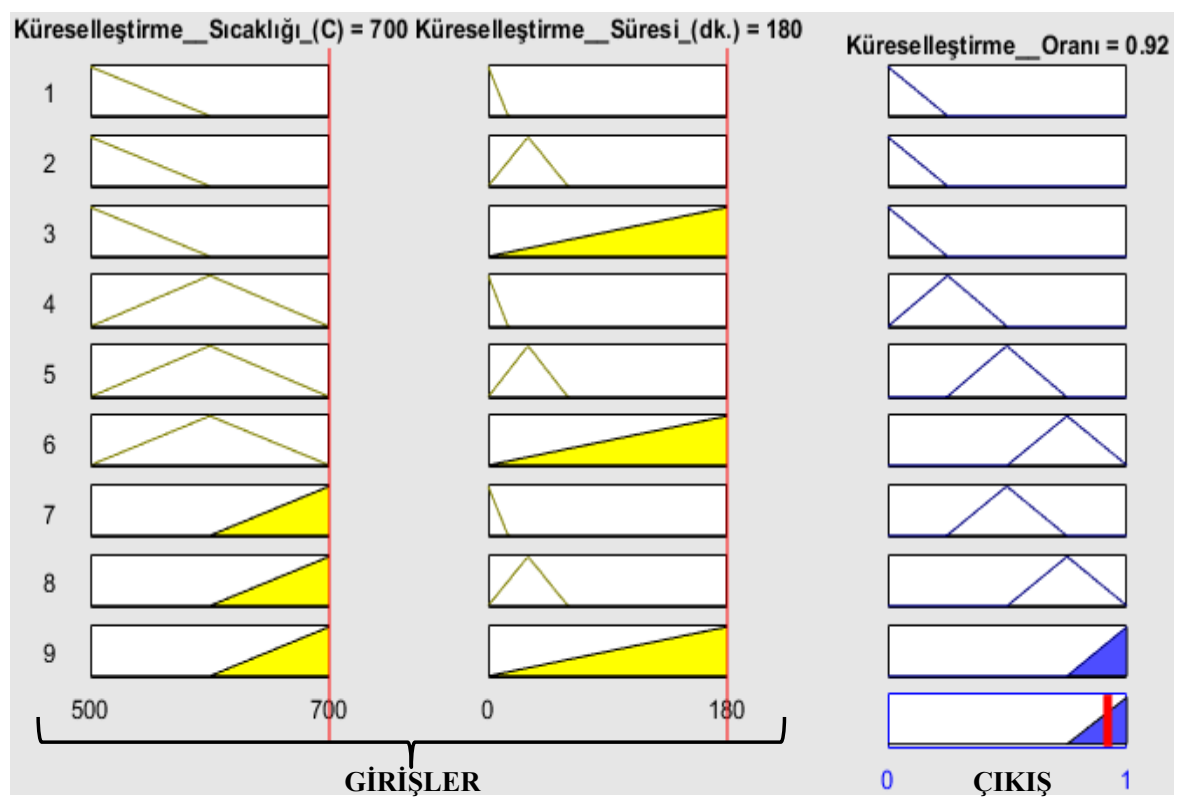

Şekil 8. Kural 9: Grafiksel gösterimi

(Figure 8. Rule 9: Graphical representation)

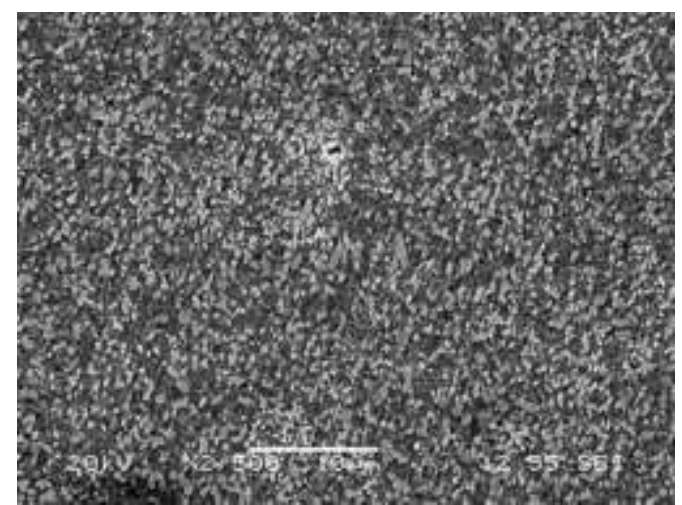

Şekil 9. AISI $1050^{\prime}$ in $700^{\circ} \mathrm{C}$ ve 90 dakikadaki SEM görüntüsü (Figure 9. SEM imagine of AISI 1050 at $700^{\circ} \mathrm{C}$ and 90 minutes)

Oluşturulan kural tabanın dışında seçilen bir örnek için mikroyapıda oluşan küreselleşme oranı Şekil 10'da verilmiştir. Şekil $10^{\prime}$ daki grafiğe bakıldığında $650^{\circ} \mathrm{C}$ ve 90 dakika ısıl işlem uygulanırsa mikroyapı içindeki küreselleşme oranı 0.782 olacaktır. Küreselleştirme sıcaklığı ve süresi şartlarına bağlı olarak oluşturulan kural tabanlarına göre küreselleştirme oranın genel yapısının gösterimi Şekil 11'de verilmiştir. Şekil 11'deki grafiğe bakıldığında küreselleştirme oranının küreselleştirme sıcaklığı ve süresinin artması ile arttığı görülmüştür. $500^{\circ} \mathrm{C}^{\prime}$ de ve 15 dakikada iş parçasının mikroyapısında her hangi bir küreselleşme meydana gelmez iken $700^{\circ} \mathrm{C}^{\prime} \mathrm{de}$ ve 180 dakikada mikroyapıda tam küreselleşme meydan gelmiştir. Sonuç olarak iş parçasının mikroyapısının küreselleşmesi hem ısıl işlem 
sıcaklığına hem de ısıl işlem süresine bağlı olarak değiştiği ve bu değişimin bulanık mantık ile analiz edilebildiği gözlemlenmiştir.

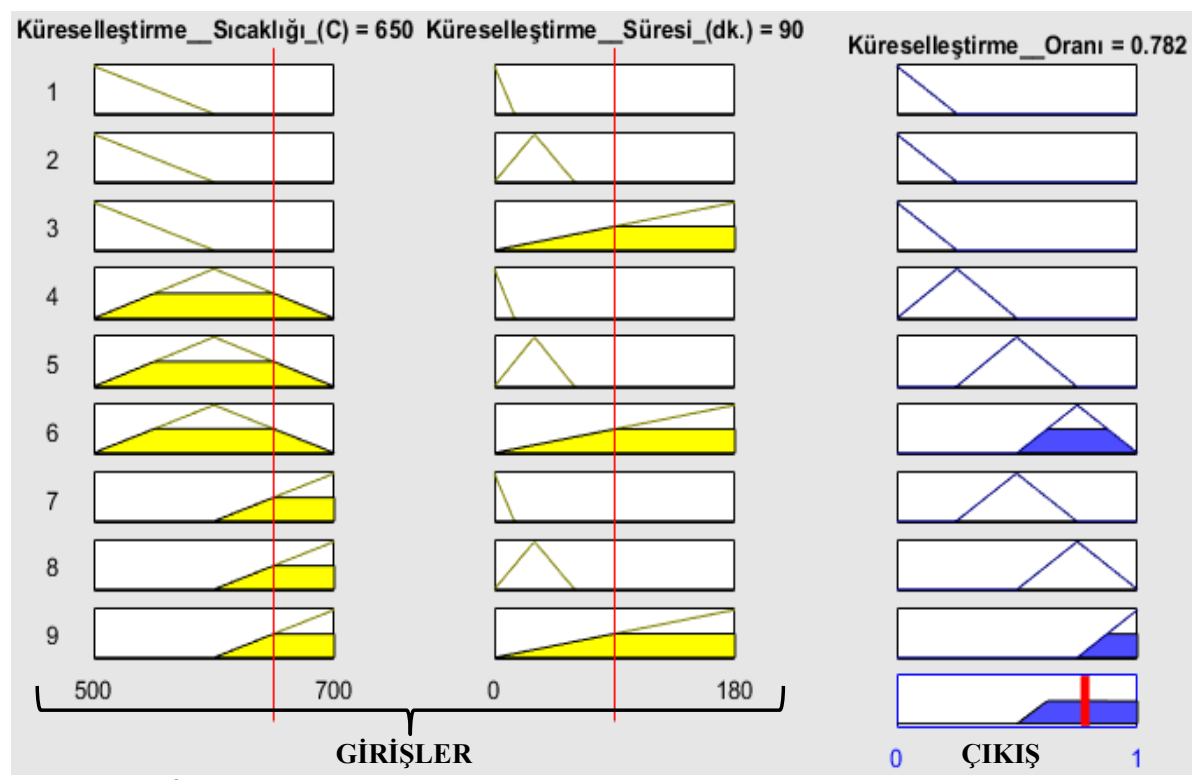

Şekil 10. $650^{\circ} \mathrm{C}$ ve 90 dakikadaki küreselleşme oranı tahmin grafiği (Figure 10. The prediction graphic of spheroidization rate at $650^{\circ} \mathrm{C}$ and 90 minutes)

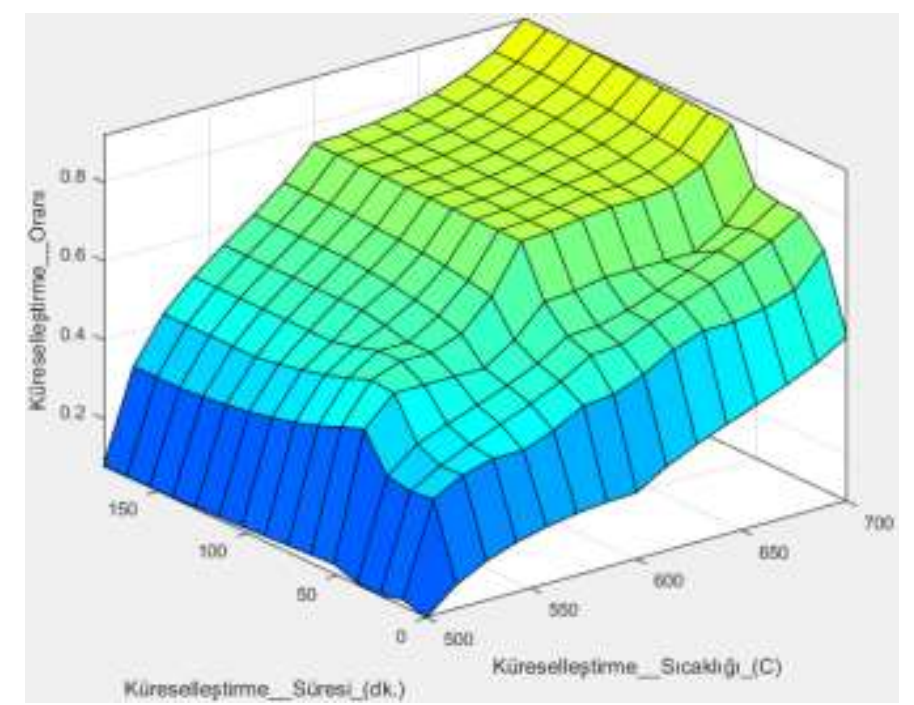

Şekil 11. Küreselleştirme oranın yüzey grafiği

(Figure 11. The surface graphic of the spheroidization rate)

\section{SONUÇ VE ÖNERILER (CONCLUSION AND RECOMMENDATIONS)}

Gerçekleştirilen bu çalışmada, mikroyapısı martenzit faza getirilmiş orta karbonlu çelik malzemeye farklı sıcaklıklarda ve farklı sürelerde ısıl işlemler uygulayarak mikroyapı değişimleri bulanık mantık ile modellenmiş ve malzemedeki değişim bulanık mantık ile tahmin edilmeye çalışılmıştır. Yapılan bu çalışma sonucunda şu sonuçlar elde edilmiştir.

- Küreselleştirme sıcaklığı ve küreselleşme süresi artıkça orta karbonlu çeliğin mikroyapısındaki küreselleşme oranı da artmaktadır. 
Baday, Ş., Başak, H. ve Sönmez, F., Technological Applied Sciences (NWSATAS), 2A0122, 2017; 12(4):153-162.

- $500^{\circ} \mathrm{C}$ hiç küreselleşme elde edilmezken, aksine $700^{\circ} \mathrm{C}$ tam küreselleşme elde edilmiştir.

- Dilsel ifadeler kullanılarak orta karbonlu çeliğin mikroyapısındaki küreselleşme oranı başarılı bir şekilde belirlenmiştir.

- Bulanık mantık kısıtlı kural oluşturma yolu ile yüksek tahmin becerisi geliştirmiştir.

- Bulanık mantık bu mühendislik probleminin çözümünde etkili olarak kullanılabilecek bir yöntem olarak öne çıkmıştır.

\section{NOT (NOTE)}

Bu Çalışma 5-8 Eylül 2017 tarihinde Gürcistan-Tiflis'te düzenlenen " 2 nd International Science Symposium (ISS2017)" sempozyumunda sözlü bildiri olarak sunulmuştur.

\section{KAYNAKLAR (REFERENCES)}

1. Adalı, Y. ve Kurnaz, C., (2003). 5140 Çeliğinin Küreselleştirme Isıl İşlemi ve Mekanik Özelliklerinin İncelenmesi. SAU Fen Bilimleri Enstitüsü Dergisi, Cilt:7, Sayı:1, ss:251-258.

2. Baday, Ş., Başak, H. ve Güral, A., (2015). Küreselleştirme Isıl İslemleri Uygulanmış Orta Karbonlu Çeliğin Mikroyapı ve Sertlik Değerlerinin İncelenmesi. Batman Üniversitesi Yaşam Bilimleri Dergisi; Cilt:5, Sayı:1, ss:66-77.

3. Altuntaş, O. ve Güral, A., (2015). Yüksek Karbonlu Sinterlenmiş Çeliklerin Darbe Tokluklarına Küreselleştirme Isıl İşlemlerinin Etkisinin İncelenmesi. Politeknik Dergisi, Cilt:18, Sayı:3, ss: $107-112$.

4. Başak, H. ve Baday, Ş., (2016). Küreselleştirilmiş Orta Karbonlu Bir Çeliğin İşlenmesinde, Kesme Parametrelerinin Kesme Kuvvetleri ve Yüzey Pürüzlülüğüne Etkilerinin Regresyon Analizi İle Modellenmesi, Pamukkale Univ Muh Bilim Derg, Cilt:22, Sayı:4, ss:253-258.

5. Baday, Ş., Başak, H. ve Güral, A., (2014). Aşırı Temperleme Isıl İşlemi Uygulanmış Orta Karbonlu Çeliğin Kesme Kuvvetleri ve Yüzey Pürüzlülüğü Açısından Íncelenmesi. Makine Teknolojileri Elektronik Dergisi Cilt:11, Sayı:4, ss:1-9.

6. Karnyabi-Gol, A. and Sheikh-Amid, M., (2010). Spheroidizing Kinetics and Optimization of Heat Treatment Parameters in CK60 Steel Using Taguchi Robust Design. Journal of Iron and Steel Research. Volume:17, Number:4, pp:45-52.

7. Gajalakshmi, K., Palanivel, S., Nalini, N.J., Saravanan, S., and Raghukandan, K., (2017). Grain Size Measurement in Optical Microstructure Using Support Vector Regression. Optik, Volume:138, pp:320-327.

8. Adalı, Y. ve Kurnaz, C., (2003). 5140 Çeliğinin Küreselleştirme Isıl İşlemi ve Mekanik Özelliklerinin İncelenmesi. SAU Fen Bilimleri Enstitüsü Dergisi, Cilt:7, Sayı:1, ss:251-258.

9. Barzani, M.M., Zalnezhad, E., Sarhan, A.A.D., Farahany, S., and Ramesh, S., (2015). Fuzzy Logic Based Model for Predicting Surface Roughness of Machined Al-Si-Cu-Fe Die Casting Alloy Using Different Additives-Turning. Measurement, Volume:61, pp: $150-161$.

10. Dewangan, S., Gangopadhyay, S., and Biswas, C.K., (2015). Multi-response Optimization of Surface Integrity Characteristics of EDM Process Using Grey-Fuzzy Logic-Based Hybrid Approach. Engineering Science and Technology, an International Journal. Volume:18, pp:361-368. 
11. LV, Z.Q., Wang, B., Wang,Z.H., Sun, S.H., and Fu, W.T., (2013). Effect of Cyclic Heat Treatments on Spheroidizing Behavior of Cementite in High Carbon Steel. Materials Science \& Engineering A, Volume:574, pp:143-148.

12. Ibrahim, A.A., Abd Rabbo, S.M., El-Axir, M.H., and Ebied, A.A. (2009). Center Rest Balls Burnishing Parameters Adaptation of Steel Components Using Fuzzy Logic. Journal of Materials Processing Technology, Volume:209, pp:2428-2435.

13. Fedai, Y. ve Ünüvar, A., (2014). Frezelemede Optimum Kesme Parametrelerini Belirlemek İçin Yapay Zeka Sistemlerinden Oluşan Adaptif Bir Sanal Operatörün Geliştirilmesi. 5. Ulusal Talaşlı İmalat Sempozyumu, Bursa, Türkiye, Bildiri.

14. Orak, İ.M., ve Erkaymaz, H., (2011). Soğuk Haddehane Tandem Sisteminin Bulanık Mantık İle Modellenmesi. 6th International Advanced Technologies Symposium (IATS'11), Elazığ, Turkey, Bildiri.

15. Acar, M., Haberler-Weber, M., and Ayan, T., (2008). Bulanık Çıkarım Sistemleri İle Heyelan Bloklarının Belirlenmesi: Gürpınar Örneği. Jeodezi, Jeoinformasyon ve Arazi Yönetim Dergisi, Cilt:1, Sayı:98, ss:28-35.

16. Karahan, M. and Şen, E.Z., (2003). Nehirlerdeki Askı Maddesi Miktarının Bulanık Mantık İle Modellenmesi. İTÜ Dergisi/d Mühendislik, Cilt:2, Sayı:3, ss:43-54.

17. Gani, A., Açıkgöz, H., Keçecioğlu, Ö.F., and Yılmaz, Ş., (2014). Lineer Olmayan DC Servo Motorun Bulanık Mantık Denetleyici ile Hız Denetimi. Elektronik-Bilgisayar ve Biyomedikal Mühendisliği Sempozyumu, Bursa, Türkiye, Bildiri. 